\title{
HUMANISMO, HISTORIA Y TEATRO EN EL RENACIMIENTO: EL FENÓMENO ITALIANO*
}

\author{
Por Rafael MAESTRE
}

A Santiago Payá y familia

En las décadas finales del siglo XV empiezan a evolucionar los espacios escénicos con respecto a los medievales en función del desarrollo de los géneros dramáticos. El conocimiento que se tenía de la comedia antigua romana, como era el de manuscritos de Plauto, Terencio y Séneca que habían conocido los anaqueles de los monasterios, y posteriormente, los de las universidades, ahora, gracias al espíritu investigador del Renacimiento, iban a pasar a ser materia, nuevamente, escenificable.

\section{Arquitectura}

Aún en las primeras puestas en escena de algunos de los autores mencionados, el espacio todavía sería, en buena medida, semejante o heredero del medieval. El Foro de Roma conocería con tablado, estrado o escenario fabricado exprofeso para ello la obra de Séneca, Hipólito, en $1486^{(1)}$; trabajo teatral que pasaría despés, en tablados o escenarios más o menos improvisados, levantados en los patios, al aire libre, al castillo de San Angelo y al palacio del cardenal Rafael Riario. Y en el mismo espacio, el patio, la pieza de Plauto, Menaechmi (Los Gemelos), con puesta en escena de P. Prisciani, también en este año, producida por la familia d'Este en su palacio de Ferrara. Lo que viene a señalar a este nuevo teatro como un factor influyente en la evolución de la arquitectura en los palacios ya que éstos como las villas y otros elementos arquitectónicos urbanos están a la búsqueda de nuevas fórmulas al ir convirtiéndose en un nuevo marco para la vida social. A lo que habría que sumar la decadencia de las representaciones sacras,

* Este trabajo recoge un resumen de la memoria de licenciatura que bajo la dirección del Dr. D. Enrique Giménez López fue defendida en la Facultad de Filosofia y Letras de la Universidad de Alicante. 
excepto en la capital de la Emilia que conservan aún un gran esplendor, en esta expansión del teatro, desde 1470 a 1550 , y el auge de las cortes de Roma, Ferrara primero y Mantua, Urbino después, a las que se unirán luego Florencia y, con menos brillantez, Venecia.

Si algo aportan estos dos reestrenos, puesto que hay que tener presente que en sus respectivas épocas tuvieron su «premier», como elemento innovador, en lo que afecta al multiplano medieval o escenario simultáneo de la Baja Edad Media, es precisamente el uso de la «scaenae frons» romana provista de puertas de entrada,en el mismo plano, una al lado de otra.

En la referida fecha, 1486, iba a aparecer la obra de Vitruvio, De Arquitectura, edición a cargo de Johanus Sulpicio de Veroli; Johanus había puesto sus conocimientos del mencionado tratado(2), antes de publicarlo en una edición preferentemente filológica, al servicio teatral de Pomponio Leto, director, para la representación de Hipólito del cordobés. No en vano, el Verolano, dedica la publicación a Riario aludiendo a los esfuerzos del cardenal por restituir el teatro a Roma: un estrado en el forum, una escena en el castillo de San Angelo y en su propio palacio bajo un toldo ${ }^{(3)}$.

Así esta influencia se vería en los cinco pies de altura del escenario, con una escena única pintada, a manera de telón de fondo; a la que hay que suponer que los elementos corpóreos que cita Vitruvio para la escena trágica ${ }^{(4)}$, fueran realmente los existentes en el foro romano. Espectáculo que no gozaría de estos últimos al trasladarse a los patios. La producción de la Casa d'Este, de la mano de su prócer Ercole, indica una mínima influencia vitruviana y una gran afinidad con lo medieval hasta en la decoración corpórea, ya que tuvo lugar sobre un «tablado con cinco casas almenadas. Había, en cada una de ellas, una ventana y una puerta.... ${ }^{(5)}$.

El palacio de Riario, desde su proyección, intentaba aportar la forma arquitectónica como lugar para el hecho teatral al tentar la cortile( ${ }^{(6)}$, aunque precedentes de ésta existían en Florencia, en la labor de Michelazzo, en el palacio Médicis, como especie de adaptación civil o profana del claustro en el lugar común o de convivencia del palacio o mansión; espacio al que Roma proveerá de mayor ostentación que poseía el toscano. En su construcción, iniciada en 1483, el cardenal español, lo dota de un patio cuadrado, unas arcadas de tipo toscano en el interior y romano en los pórticos superpuestos; de este modo la cortile cuadrada o cortile carrèe aparece como la cavea donde se desarrolla el nuevo espectáculo, situándose los espectadores en los pisos que sirven de palcos o sobre bancos en el patio, embocando el marco de los pórticos al estrado o púlpitum.

Así preferentemente a partir de estos años, comienza a darse un desarrollo y auge de esta concepción escénica vitruviana y del decorado único, favorecido por la labor de mecenazgo que prestan príncipes, cardenales y papas, etc.; como, por ejemplo, el proyecto de Bramante para el patio del mirador en los jardines del Vaticano que reunía, como parte integrante de una misma estructura arquitectónica, los elementos diferenciados del jardín, de la plaza para justas y torneos y de las gradas para los espectadores. Dicho conjunto debía componer la gran cortile del Belvedere o el «gran teatro» privado del Papa y su corte.

Son años en los que se representan: Los Hermanos y el Cartaginés de Plauto 
en el patio del Marqués de Mantua, en 1490; en 1491, la Andria y en 1499, el Eunuco de Terencio ${ }^{(7)}$.

De los patios o espacios al aire libre se pasa a interiores y la arquitectura con esto alcanza una nueva dimensión gracias a los logros de la perspectiva. Poco tiempo después, la misma Roma, con su emplazamiento en el Capitolio, iba a tener ocasión de ver Poenulus (El Cartaginés) ${ }^{(8)}$ de Plauto - veintitrés años más tarde de que se hiciera en Mantua- bajo la dirección del bibliotecario del Vaticano, Tomás Inghirami, discípulo de Pomponio Leto. El escenario se situó entre el palacio de los senadores y el de los conservadores, «un escenario al aire libre con cinco puertas ${ }^{(9)}$. En este teatro de madera se evidencia un principio de instalación que encontramos en las descripciones de espectáculos dados en sala, o más propiamente en una cortile cubierta de un toldo, de representaciones nocturnas con luz artificial; la sala y la escena están concebidas como un conjunto arquitectónico que se conjuga con la normalmente opulenta decoración, ocupando la escena uno de los lados del rectángulo y las gradas, elevadas sobre plataformas a la misma altura que la escena, copan los tres lados, situándose los bancos en el patio. Esta distribución del espacio teatral obliga a los espectadores de los lados de las gradas a girar la cabeza para poder contemplar la escena, circunstancia que responde a imperativos de orden social ${ }^{(10)}$. Ya en 1513 este teatro, una construcción provisional alzada - proyecto probable de Julián de Sangallo- sobre la plaza del Capitolio, constituía el marco destacado del programa celebrativo con motivo de la concesión de la ciudadanía romana a Julián y a Lorenzo de Médicis, hermano y nieto del Papa León X, respectivamente; la arquitectura trabada, cerrada arriba por un toldo, ricamente adornado con decoraciones pictóricas, se destinaba a albergar en un mismo lugar los diversos momentos característicos de una fiesta del Renacimiento: el desfile de los triunfos y carros alegóricos, el banquete o festín y la representación de una comedia clásica. Este episodio de las fiestas romanas de 1513 puntualiza un momento emblemático en el proceso de recuperación del teatro clásico en la cultura humanística.

Poco antes de este trabajo de Inghirami, Ludovico Ariosto tiene ocasión de estrenar su Cassaria , 1508, en una sala rectangular convertida en teatro, en la sede palaciega de los Este de Ferrara; en la que el escenario ocupa el fondo de la misma y los graderíos el resto, situándose las damas en la zona central y los caballeros en las laterales. Un año después estrena en la misma ciudad emiliana Suppositi, donde la acción de dicha obra sucede en esta población sede de los d'Este.

En esta ciudad, en 1565, se erigirá, en la sala del Gran Palacio ducal, el teatro de la comedia que albergará fiestas en las bodas de Alfonso II con Bárbara de Austria, disponiendo de un aparato arquitectónico y escenotécnico semejante al salón vasarino de Cinquecento.

La misma pieza, Suppositi, será representada, en 1519, en Roma, con decorado de Rafael Sanzio, en el Vaticano(11) ante el Papa León X por iniciativa del cardenal Cibo, en una sala habilitada para dar cabida a 2.000 espectadores, con un escenario que figuraba Ferrara en perspectiva. Rafael a fin de jugar con el efecto sorpresa utilizó el telón, ocultando el decorado, que como cortina, accionaba al modo del teatro antiguo latino, al principio de la representación, caía en un foso abierto delante del escenario. Paolucci, secretario de la embajada ferra- 
rense, informaba así a su príncipe: «...allí sólo se habla de las mascaradas y de las comedias... y del aparato de Rafael de Urbino confeccionado para las mismas» ${ }^{(2)}$. Vuelto el Ariosto a la capital de la Emilia, hacia 1531-32, tras rehacer alguna de sus comedias anteriores, se dispuso a construir en el teatro de la Corte una escena permanente que fue muy elogiada pero antes de un año se quemó. ${ }^{(13)}$.

Es también a Ludovico al que hay que atribuir la instalación de una serie de avances que ya eran, en cierto modo, usuales en el teatro y aparecían configurados en la puesta en escena de La Calandria con decorado de Girolamo Genga.

Estrenada en Urbino, en 1513, esta pieza del cardenal Bibbiena disponía de un decorado en profundidad. Baltasar de Castiglione en una carta al conde L. Canosa le escribía acerca del escenario: «Se ha figurado una ciudad con calles, palacios, iglesias y torres y todo representado en relieve» ${ }^{(14)}$. Al siguiente año se escenifica en Roma, ante el Papa León X, y Baldassarre Peruzzi creó un escenario que era «no sólo fingido sino real» (15) y «no sólo pintado sino espacial» (16). Del telón o foro escénico meramente pintado, se pasó a un espacio por el que se podía andar, escalonado en un proscenio, en un escenario decorado practicable y el telón de fondo o foro pintado en perspectiva, con utilización de luz artificial ${ }^{(17)}$.

En ese paso la renovación teatral renacentista ha dado dos tipos de escena: antigua y moderna; la puesta en escena del Capitolio nos habla del primer tipo: scaenae frons provista de cinco puertas cubiertas de cortinas, sobrecubiertas de frisos de estuco, de falsa óptica, en busca de perspeciva y de cada lado, pared o muro que se revuelve en escuadra con una abertura que da acceso al foro; $\mathrm{Me}$ naechmi en Ferrara, lo hace hacia el segundo: el uso de casas practicables, con puertas y ventanas, alineadas no en función del público sino en la composición de un conjunto unificado para conseguir la perspectiva. De ahí que se reflejen elementos convencionales que ya había utilizado el teatro medieval y por ello el afán de búsqueda para alcanzar el decorado único, sin llegar a aplicar eficazmente el poder integrador de la perspectiva. Por eso la experiencia del teatro en la cortile tiende a retardar la determinación más precisa de las cuatro combinaciones teóricamente posibles que dominan el desarrollo del lugar teatral.

\section{«Espectador (sala)}

Teatro provisional

Formas de transịción

Teatro estable
1. Peldaño de madera

2. Peldaño de madera

3. Arquitectura (cávea)

4. Arquitectura (cávea) actor (escena)

estrado de madera escena monumental

estrado de madera escena monumental. ${ }^{(18)}$

La escena realizada en piedra aparecía en Lorea gracias al patricio paduano A. Cornaro, gran amante de la arquitectura, que tuvo a su servicio al pintor Falconetto para que le ayudase a diseñar dos estructuras de jardín en el patio de su palacio, siendo una de ellas este teatro estable o fijo, al que los diseños del pintor veronés datan de 1542 . Previamente a este diseño en una escena alegórica de la 
Anunciación, como fondo de cuadro, presenta una vista urbana que parece tener una semejanza con los arquetipos de inspiración vitruviana: a la izquierda, la escena cómica; en el centro, la trágica y a la derecha, la festiva. El edificio que alza, haciendo referencia al paramento escénico del teatro clásico, acogía las representaciones de las comedias de Angelo Beolco.

El binomio Cornaro-Falconetto pretendía hacer un teatro «a imitación de los antiguos y que el lugar de la escena sea de piedra perpetua y que la parte donde se sitúa el auditorio sea de madera portátil, que se pueda cambiar... ${ }^{\left({ }^{(19)}\right.}$. Esta escena arquitecturada a la logia con arcadas a las que se superponen frontones, encuadrados de nichos y ornamentos, aparecería luego, de manera muy semejante, en el período manierista. De este modo la analogía con la scaenae frons romana evoluciona en función de la nueva concepción de la escena ya que la cortile es menos tratada como una cavea rectangular que como una fachada de teatro.

Tal teatro sería conocido por Andrea Palladio al pasar de Vicenza a Padua, adonde acompañó a su protector Trissino durante tres años, desde 1538 a 1541; $y$, precisamente, por estas fechas Sebastiano Serlio, discípulo de Peruzzi, que trabajaba en Roma, se había trasladado al Véneto para diseñar un teatro provisional de madera en el patio del palacio de Porto, al mismo tiempo que preparaba sus siete libros sobre arquitectura, publicando el tercero y cuarto en Venecia, en 1537 y 1540 . «Eran los primeros libros impresos en los que la imagen prevalecía sobre la palabra como transmisor principal de inforamción y estilo de las artes ${ }^{(20)}$ dado la profusión de ilustraciones ricamente realizadas con grabados de madera y de los que una parte era heredada de Peruzzi, «...A Roma lavora del 1514 al 1527 c.,inseme a Baldassarre Peruzzi, che gli lasció-secondo la sua stessa testimonianza-un gran número de disegni poi, in qualche modo confluiti nel trattato... (2) . Al ampliar Palladio sus conocimientos con la obra de Serlio, venía a recoger también los ecos de la experiencia romana del ámbito Rafael-PeruzziBramante, amén de los propios del boloñés. Invitado por D. Barbaro a colaborar en la edición que preparaba de la obra de Vitruvio, el paduano hizo, junto a otros diseños, la reconstrucción del teatro de Vitruvio pero con el conocimiento que le suponía el bagaje serliano; lo que Andrea trataba de superar, en lo que respecta a la descripción de la escenografía ilusionista, era la fórmula peruzziana para llegar a una reedificación arqueológica total. Dicha fórmula desarrollada por Baldassarre e ilustrada por Sebastiano consistía en el uso de plataformas al fondo de las cuales aparecían calles urbanas, jardines, etc. hechas a base de escorzos para que asemejasen lo más posible al modelo real.

Ocasiones, de poner a prueba este criterio, las vino a tener cuando la Academia Olímpica de Vicenza le encargó la construcción de teatros provisionales para representaciones de obras de Piccolomini y Trissino, en 1561-62; para la del primero utilizó el gran salón de la Basílica, empleando en la del segundo, su exprotector, un escenario mayor con capacidad para ochenta actores y perspectivas rurales, así como urbanas realizadas en tres dimensiones.

Casi veinte años después la Academia pone en manos de Palladio la oportunidad de reconstruir, aunque en buena parte sea idealmente, un teatro romano antiguo. Labor que realizará en madera y estuco y tendrá comienzos, con maqueta previamente preparada por el paduano, en 1580. El trabajo de construcción 
principia «dentro il cortile delle publiche case alla piazza dell' Isola»(22). El escenario tenía un piso plano y otro más elevado que se apoyaba en la pared o muro largo con tres puertas y flanqueado con otras dos más pequeñas, cada una en una entrada, siendo estas dos más pequeñas laterales las que dan acceso al proscenio. Cambios introducidos en el proyecto impidieron el empleo de figuras alegóricas en la galería de columnas de la pared del escenario, colocando estatuas de miembros de la Olímpica.

Siguiendo a Serlio utilizó un punto de mira situado detrás del escenario, hacia el que orientó la perspectiva de sus tres puertas, reforzando de esa manera la ilusión de profundidad, aunque las perspectivas de calles no figuran así en su diseño para la edición de Vitruvio y sí la idea de que sean periactois que no llevaría a cabo, no sólo por su muerte, acaecida en agosto de 1580, sino por encontrarse muy condicionado por el espacio disponible; se obligaba a colocar el escenario en los huecos del proscenio, ${ }^{(23)}$ debido a que no tenía terreno suficiente el teatro ya que en el año siguiente de su muerte, los de la Academia, deciden comprar más tierra: «... che será bisogno per fare la prospettiva senza la cuale non si potrà dar perfezione alla fabbrica...»;(24) $\mathrm{o}$, también que pensara cerrar las puertas secundarias, no las del proscenio, por medio de telones de foro pintados en perspectiva, falsa. Para la abertura o puerta central de dicho muro o pared de escenario, Palladio, adoptó como scaenae frons, a la que ayudarían las falsas perspectivas, el arco de triunfo romano; elemento éste que los conquistadores romanos contruían para celebrar su regreso de las campañas victoriosas y que mantenido a lo largo de la época medieval lo revitalizaba, literariamente para fuente de construcción ilusoria, Petrarca. ${ }^{(25)}$

A ello Vicenzo Scamozzi, continuador de la obra del paduano, introducirá cambios que significarán el que detrás de las cinco entradas se construyan vistas breves de calles, tres salían del arco central, divergentes, con adornos tridimensionales, a fin de conseguir ilusión aunque daban una perspectiva muy forzada.

$\mathrm{El}$ hemiciclo o cavea en que se hallaban los espectadores con trece filas de asientos, seguía la forma de una elipse en lugar de un semicírculo, con lo que brindaba mejores líneas visuales y mayor intimidad, enlaza inmediatamente con la pared del escenario, consiguiendo así una unidad de cavea y escena, que sólo se verá rota por la luz al ser un teatro cubierto, lo que supone un mismo techo para dos espacios: iluminación artificial instalada sobre un friso que, en cierta medi$\mathrm{da}$, rompe con la unidad de sus espacios complementarios. Una vez acabado y tras un año de ensayos, en 1585 , en el último día de Carnaval, se inauguraba con la obra de Sófocles, Edipo Tiranno, en versión de O. Giustiniani, música de A. Gabrielli y puesta en escena de A. Ingegnieri.

La Casa de Gonzaga, en Mantua, hacia finales de su dinastía, manteniendo su mecenazgo por el arte escénico, llama a Scamozzi para la construcción de un teatro, destinado a la Academia de los Confidenti, enmarcado en una fortaleza pentagonal de Sabbionneta; acordado Vicenzo con el prócer Vespasiano se inician las obras que culminan en 1590. La influencia de Palladio, así como la de Serlio van a ser notorias. Vicenzo mantiene el criterio seliano al crear una escena sin marco y en la pared de fondo un decorado fijo, por lo que la escena queda estructurada en dos partes. Trabajo al que suma la experiencia desarrollada por la 
corte florentina, continuadora de una práctica tradicional toscana, en el teatro mediceo del que toma, aunque a escala más pequeña, la planta rectangular, el cielo con lacunaris azules pespunteado de bollones de oro que simula el firmamento, el pavimento de la sala en pendiente hasta el proscenio y los pequeños arcos o nichos pintados sobre la pared y decorados de hundida perspectiva; el peristilo que circunda la cavea, lo corona de estatuas de divinidades olímpicas y lo remata con bustos a la romana.

En esta escena a la zona de atrás corresponde un plano inclinado y decorado en perspectiva, en escorzo, o sometido a una disminución y limitado por un lienzo o telón de fondo con fasas perspectivas; en la zona delantera, una plataforma horizontal limitada del lado del público por el muro de la escena, y, en ambos lados unas escaleras permiten la comunicación escena-cavea, siendo el proscenio un arranque frontal de esta plataforma delantera pero a menor nivel de altura.

Scamozzi emplea los mismos criterios con los que había acabado la obra de Palladio: el aumento de la profundidad de la perspectiva, salida a nivel de proscenio, de calles al otro lado de la abertura central y por consiguiente el ensanchamiento del arco de triunfo; lo que le lleva a un mayor poder de sugerencia del decorado de fondo y una mejoría de la visión ya que si la perspectiva central favorece a los espectadores situados en el punto medio del hemiciclo o cavea, las perspectivas secundarias hacen lo mismo con respecto a los espectadores más alejados del eje central; factores aquí más notorios por cuanto que era un teatro pequeño y había que renunciar a algunas entradas, quedando la escena a única vist$\mathrm{ga}$, que comenzaba en los extremos laterales del escenario, «como un solo proscenio»?.(26)

La escena, a única vista, en las trazas de G. Battista Aleotti, el Argenta, se convierte en un escenario profundo, un amplio proscenio y una orquesta más ancha aunque menos profunda que el escenario, cuando por encargo de la corte de los Farnesio deje preparado el teatro de Parma en 1618, situado en la primera planta del Palacio de la Pelota. Previamente Jacopo Barozzi, el Vignola, ya había trabajado para esta familia cuando en el 1558 proyectó un teatro estable al aire libre en el jardín del palacio de Plasencia; el Vignola en el teatro para Eduardo Farnesio intenta «una imitación de los antiguos», por lo que dispone un monumental graderío en el fondo del patio que debía servir, además, para fiestas y carrozas.

En la realización del Argenta el hemiciclo o cavea está dispuesto en forma de herradura, con gran capacidad de espectadores, siendo un gran espacio el que queda para patio, entre orquesta y cavea -en ocasiones orquesta y patio, o solamente la primera serán empleadas para naumaquías - situándose las entradas o puertas del teatro, no de la escena, en los laterales del mismo, a espacios entre la cavea y la escena; apareciendo la influencia serliana, en la visión palladiana, en el alto coronamiento de la cavea, ${ }^{(27)}$ que en su eje central posee un palco para Su Alteza Serenísima, así como también la expresión de su bagaje práctico ferrarense, cuando a finales del Quinientos labora en la logia llamada el Teatro en el jardín del Palacete de Marfisa d'Este que acogía representaciones y entretenimientos musicales, donde G. Battista repite la síntesis de los dos elementos: la escena en el pórtico y la decoración interna en la pérgola, que vuelve a la primitiva imagen del 
bosque ameno. A pesar de su uso frecuente en los espectáculos cortesanos, en sus principios el Teatro Farnesio de Parma no tiene telón de boca.

De igual modo en el amplio ámbito farnesiano del Argenta, realizado para el matrimonio del duque Eduardo con una princesa de la Casa de Médicis, los ecos o influencias del Teatro mediceo de los Uffizi son varias: la cavea en forma de $U$ alargada, el revestimento de la pared con arcos, el escenario con proscenio, decoraciones en la embocadura o bocana, amplios espacios para máquinas y otros útiles; como, al igual la simbiosis con elementos florentinos, son evidentes en relación a Sabbioneta, los recuerdos y los influjos de Palladio, como son el estilo serliano de las arcadas, imitadas de la Basílica vicentina.

Son estas bodas de Eduardo Farnesio con Margarita de Médicis las que dan lugar, diez años después de su preparación, a su inauguración oficial con el espectáculo, el torneo coreográfico Mercurio y Marte sobre versos de C. Achellini musicados por Monteverdi y Peri, que concluyó con una naumaquía a imitación de las florentinas. Para festejar el mismo acontecimiento, en octubre de este mismo año de 1628, era representada en Florencia, en el Teatro Médicis, La Flora de A. Salvadori, con música de M. Gagliano, escenografía y decorados de Alfonso Parigi y máquinas de Giulio Parigi.

Coetáneo al de los Confidenti y anterior al de los Farnesio se alza el teatro de los Médicis en los Uffizi. El origen de esta instalación se localiza en el jardín; los Médici lo transforman en un lugar de espectáculo para lo que delimitan el patio con una galería de grandes arcadas que ilustran la gloria de la familia, decoran las paredes del recinto, repitiendo el motivo de los triunfos pintados por Mantegna, el de César, que hiciera para una sala del palacio regio gonzaguesco de Mantua, a fin de homenajear la visita que hace a Florencia, en 1533, Margarita de Austria, hija del emperador Carlos V y novia del duque Alejandro; pero son seis años más tarde cuando se da la metamorfosis definitiva, durante las fiestas de boda del duque Cosme I con Eleonor de Toledo, en la preparación de la puesta en escena, de la obra de A. Landi, El Comodo con intermedios de escenas alegóricas y musicales, a cuyo cargo se encontraba Bastiano de Sangallo.

Las mujeres se sitúan en las gradas dispuestas a lo largo de las alas mayores mientras que los hombres lo hacen en banquetas en el centro del patio y el príncipe junto con la corte lo contemplan desde un dosel colocado en la logia al fondo; el palco con la escena se levanta al lado opuesto del jardín y un toldo recubre el espacio del patio. ${ }^{(28)}$

De este espacio se pasa, al año siguiente, 1540, a la sala trapezoidal contigua al Palacio del Cronista que es adaptada por Giorgio Vasari, con la supervisión de Cosme de Médicis, para una nueva sala de representaciones en la que busca magnificar su autoridad. ${ }^{(29)}$ Lo consigue al dejarla reducida, mediante la rectificación de dos tabiques, a planta de forma rectangular y realza el techo con una decoración de lacunaris, siguiendo un programa iconológico proyectado por V. Borghini: en el centro, un paraíso, se encuentra el disco de la gloria de Cosme, repitiendo la iconografía de los «ingegni» de Brunelleschi, en una apoteosis que recuerda la disposición de la corte celestial -elemento que conocía bien Giorgio y procuró su continuidad en la Iglesia del Espíritu Santo - ya que la impostación figurativa repitiendo la del ingegni del Paraíso, atribuía a la figura del príncipe y su corte 
una serie de alusiones propias de la naturaleza divina; ${ }^{(30)}$ decorando las paredes, amplias, con escenas de victorias mediceas. La sala se disponía así para recibir sobre su lado menor, orientado hacia el mediodia, el dispositivo de un palco para los espectáculos.

Estos antecedentes y consecuencias, a caballo y en equilibrio de las experiencias del jardín del Palacio Médicis y su perfeccionamiento en el Salón del Cinquecento, se pueden concretar en el trabajo que Vasari realiza en Venecia, en un palacio no identificado situado en Cannaregio, en 1542 para la puesta en escena de la obra del Aretino, Talanta, a cargo de la compañía de la Calza, I Sempiterni, quienes en su bautismo teatral habían presentado una escenificación con escenografía de Tiziano.

Esta relación florentino-veneciana acrecienta su influencia en el Salón del Consejo Mayor del gran palacio ducal; sala destinada a las asambleas de la máxima magistratura veneciana que servía excepcionalmente para la celebración de acontecimientos sociales, como en 1574, que fueron preparados en él banquetes, bailes y la representación de una tragedia, con motivo de la visita de Enrique III de Francia. Su similitud con el modelo del Salón del Cinquecento se aprecia en la Apoteosis de Venecia de Veronese, que campea al lado de la apoteosis o gloria de Cosme I en un amplio óvalo del Paraíso.

El carácter y fin festivo adquiere en el salón mediceo un permamente relieve con los preparativos para recitales, banquetes y otras ceremonias que se pueden datar entre 1565 y 1569 , con ocasión de una primera serie de bodas, visitas de príncipes, etc. La concepción de las decoraciones y las escenografías, entendiendo la definición de aparato en la síntesis de ambas, junto con la maquinaria, fue siempre de Giorgio, ayudado en la iconografía por Borghini y en las instalaciones técnicas por el joven Bernardo Buontalenti.

El día de Navidad de 1565 se representa con escena de Vasari la pieza de Francesco d'Ambra, La Cofanaria, obra con seis intermedios que tenía por argumento la fábula de Amor y Psiche a partir de Apuleyo, ${ }^{(31)}$ en el ámbito de las fiestas para las bodas del príncipe Francesco con Juana de Austria, donde aplica, también, resultados obtenidos con Talanta, particularmente los nacidos de su colaboración con Aristóteles de Sangallo. Así para la pieza de Ambra había adecuado la sala con escenario que estaba encuadrado con una moldura en forma de arco, compuesto de un arquitrabe y dos soportes laterales, los cuales separaban, mediante un tabique, el lugar de la acción del lugar donde estaba el público, gradas para los espectadores y bancos en el centro de la sala, y estatuas que sostenían las lámparas.

A este Teatro de los Médici en los Uffizi, dos años después de la muerte de Vasari y Cosme, en 1574, el gran duque Francisco I manda hacerle un anexo en el Palacio de la Plaza, aprovechando el espacio fusionado obtenido en el lado oriental, para representar comedias, donde el pavimento o suelo de éste ha de ser de un lado más alto que de otro para que no sea impedida la vista a los que están detrás; labor que llevará a cabo Buontalenti, quien ha pasado a ocupar el cargo de Vasari, organizador de los festejos, decoraciones y teatro de los Médici, que pone en práctica ese deseo y consigue la concavidad del patio o piso de la cavea, a lo largo del eje longitudinal, como fruto de un contrabalanceo desde el declive 
del muro del proscenio hasta el cuerpo de la cavea o platea; espacio para el que se ocupa la Sala de Magistrados, convertida ya en de espectáculos, y a la que Bernardo dará dos tratamientos o versiones.

La primera en 1586 con motivo del matrimonio de Virginia de Médicis con César d'Este, en donde retoma la idea del teatro en el jardín, evocando en la sala, mediante una decoración de árboles, la imagen del bosque ameno y encantador.

Tres años después realiza la segunda, como parte de los actos que integran el programa de festejos para las bodas del gran duque Ferran I con Cristina de Lorena; le da a la sala apariencia de galería arquitectónica, siguiendo la línea que marcara Cosme I: espacio ilusionístico cubierto por un techo entretejido de lacunaris azules y decorado con bollos de oro, que ahora, tachonado de estrellas, evocaba el movimiento del firmamento, de tal manera que los espectadores, colocados en un hemiciclo, cavea o platea de gradas dispuestas en forma de $U$ alargada, en el centro de la cual se hallaba la logia o palco para la familia ducal, tenían la impresión de encontrarse en un patio descubierto, de forma rectangular que tenía a los lados y de esquina un porticado y enfrente el vacío o espacio abierto sobre la plaza de una ciudad imaginaria.

A esta sala de unos cincuenta metros de largo por unos veinte de ancho, Buontalenti, en su segunda versión, dota al anfiteatro o hemiciclo de cinco filas concéntricas de asientos, pasillos con escaleras, al estilo del antiguo teatro romano.

Versiones que, como hemos señalado, ejercerán influencia en Scamozzi y Aleotti, ${ }^{(32)}$ quien no sólo la aplica en el Farnesio, sino también en el Teatro de la Academia de los Intrépidos de Ferrara, donde fiel a la interpretación de la arquitectura teatral latina, fijada en el tratado de Serlio, adecúa las experiencias contemporáneas. Influencia florentina, también, en G.B. Picolomini cuando traza la planta del Teatro Grande de Siena cuya sala proyectada en 1560 por Bartolomeo Neroni para la Academia de los Intronati, fue vuelta a diseñar nuevamente un siglo más tarde, por él, por Picolomini, según proyecto que tenía en cuenta tanto los resultados del Teatro mediceo de los Uffizi como sus propias experiencias emilianas.

\section{Escenotecnia}

Los dos títulos de Plauto que se representaron en el patio , bajo el marquesado de Luis de Gonzaga, en Mantua, en 1490, no guardan relación el contenido de las obras y el decorado que realizó Andrea Mantegna para ellas; hizo un trabajo que sería pintura de una de las salas del Palacio de San Sebastián, El triunfo de César, ${ }^{(33)}$ ya nombrado, en el que «habiendo situado el plano (...) más alto que la vista del espectador (...) como de acuerdo con la perspectiva convenía hacer». ${ }^{(34)}$ Seguía de este modo, el pintor mantuano, la tradición de otros grandes artistas, como Brunelleschi que en colaboración con Donatello, G. Pecori y G. Rucellai, había organizado, en 1409 , la puesta en escena de la farsa II Grasso Legnaiuolo. ${ }^{(35)}$ Para una reposición de Menaechmi que produjera Ercole d'Este en un interior, en 1491, encargó a N. del Cogo, también dramaturgo, que «pintara una perspectiva de cuatro castillos».(36)

En 1496 Leonardo de Vinci, todavía en el multiplano medieval, levanta un decorado para la Dánae de B. Tacone, así como su teatro y escenificación en el 
Palacio de Gian Francesco Sanseverino, conde de Caiazzo, en presencia del duque de Milán; para este drama mitológico que era una transformación de la Representación Sacra, de Vinci utiliza uı decorado en perspectiva, con una bóveda formando un nicho y muros con puertas; en el fondo del nicho se sitúa un dios sobre su trono en una "almendra» envuelta en llamas. ${ }^{(37)}$ Por estas mismas fechas Ludovico Sforza manda construir un teatro en su Palacio.

La escena que se desarrolla en la ciudad de Pisa en la comedia El Comodo utiliza la perspectiva, con impostación iconográfica, y emplea un proscenio en primer plano y unas escaleras de comunicación entre el escenario y el patio de butacas.

La experiencia en Venecia de Talanta, dotada de "perspectiva a la italiana» y de periactois móviles, le permite a Vasari el dispositivo escénico para La Cofanaria, con el aparato de dichos prismas giratorios para los cambios de escena, que se hacen más ágiles al poderse montar y desmontar en ocho horas. El uso de las estatuas plateadas dispuestas en la parte más alta de la tribuna, ofrecía una eficaz iluminación; eran en número par al de las horas de duración del espectáculo y cada estatua sostenía una esfera de cristal que contenía agua de color, la cual reflejaba los rayos de una antorcha colocada detrás. La intensidad de la luz oportunamente diferenciada ya que se hacía más tenúe cerca del fondo de la sala y más intensa cerca del escenario, iluminaban la escena. ${ }^{(38)}$

La aparición de la obra de Serlio permitía divulgar, gracias a sus ilustraciones, muy buena parte de todos los aspectos técnicos de su momento teatral; ya en la construcción de Porto, Sebastiano, había experimentado las enseñanzas de reconstrucción en el plano del teatro de Marcelo, planteándose la dificultad de los cuerpos con relieve sobre el plano, como sutileza del arte de la perspectiva, entendiendo ésta en cuanto afecta a superficie, y siguiendo las descripciones especulativas de Euclides, a quien no duda en calificar de profundísimo; de ahí la necesidad básica de la geometría para el arquitecto, que lleva a Serlio a interpretar la perspectiva como: «...diró bene che prospettiva è quella cosa, que Vitruvio demanda scenografía.... (39), esto es, la frente y el lado de un edificio o cualquier cosa, superficie o cuerpo, por lo que consiste en tres partes principales o líneas: la plana de la cual nace, la que va al punto $u$ horizonte -horizonte propiamente dicho, dominio de éste y por tanto donde termina nuestra vista-, y, la de la distancia que está siempre al nivel del horizonte pero más lejano o más cercano; en este horizonte su altura se entiende al nivel de nuestro ojo. Lo que supondría en el trabajo escénico ir a la busca del escorzo. Con esto, Serlio venía a reafirmar el concepto que se tenía de la perspectiva desde Brunelleschi como regla de visión, ${ }^{(40)}$ Alberti como el cuadro de una intersección plana de la pirámide visual (41) o como en Leonardo para quien la perspectiva lineal arranca de la suposición de que viendo el ojo por pirámides cuya base descansa en el objeto, la intersección plana del haz donde confluyen los rayos visuales ha de procurar una lograda imagen de todos los cuerpos y del espacio que comprende, ${ }^{(42)}$ hasta Bramante, Rafael, J. Romano. El boloñés describe el criterio vinciniano en sucesivos minicuadros integrados, al tiempo que no evita criticar a Mantegna y hacer admirativa referencia a Genga ${ }^{(43)}$ y Peruzzi. Es el ojo, un ojo que debía permanecer inmóvil, en el lugar y la distancia previstos por el artista el que mandaba en esta situación; por eso de 
Vinci, como buen conocedor que es de que el ojo natural vee decrecidas las cosas en los extremos y curvas todas las líneas rectas, propone, aún a sabiendas de que la perspectiva natural es esférica, una perspectiva artificial plana, falsa, como afecta en el caso de la pintura puesto que este arte se vale de la perspectiva, a que «ésta entiende de la pérdida de tamaño de los cuerpos opacos, de la disminución y pérdida del contorno de los mismos y de la disminución y merma del color a gran distancia». ${ }^{(44)}$

Señala también, el discípulo de Peruzzi, Serlio porque es igualmente sabedor de que el ojo ouede producir engaño, que en casos extremos se puede tomar el artista, el perspectivo, la licencia de colocar el horizonte al punto más alto de la base del edificio o cuerpo, dejándolo a su buen juicio, porque a firma «...la prospettiva è molto necessaria all'Architetto, anzi il prospettivo non fará cosa alcuna senza l'Architettura, nè l'Architetto senza prospettiva...)..(45)

Hasta él el punto principal de la perspectiva se situaba dentro del cuadro, ahora lo sitúa detrás del foro; es decir, tras el telón de fondo del escenario con la pretensión de frenar la rapidez de los escorzos y aprovechar la ilusoria profundidad; por eso el decorado combina la perspectiva lineal o falsa perspectiva con elementos tridimensionales dado que el fondo era plano y los laterales se doblaban en chaflán, en ángulo, provisto de cornisas y otros elementos arquitectónicos.

Cuando nos habla de la escena cómica explica, entre otros temas, que la realización del decorado la hace en «telari», especie de envarillado, sobre el cual pone la tela o lienzo, cuyo conjunto constituye el bastidor, y le hace una puerta delantera, en la cara, frontal o en escorzo, según la ocasión para la que fuere necesario; generalmente en los bastidores de primer término hace alguna cosa de bajorrelieve en madera sobre elementos arquitectónicos a fin de que ayude a la pintura. De este modo el arte del pincel en los de segundo término ayuda a la creación de sombras sin realce. Previo a esta labor, por si surgen dificultades donde se tenga que ubicar, fabrica una maqueta: «...io ho sempre fatto uno modello piccolo di cartoni, legnani, ben misurato...».(46)

Escena en la que las luces irán colocadas en estatuas laterales y las del centro sobre el medio punto que recubre el friso, cuidando de que las ventanas que están en primer término, a ser posible de vidrio, papel o tela pintados, aparezcan bien iluminadas: «... gli edificit sono tutti ilumi artificiati di varii colori transparenti... $\rangle^{(47)}$

Como todos los bastidores están realizados y pintados en una falsa perspectiva, en la que todas las líneas horizontales convergían hacia atrás y abajo, en busca del punto de fuga de la escena pintada en el fondo y como las partes superiores de estos bastidores laterales, excepto los de primer término, tenían que inclinarse hacia abajo, a la captura del punto de fuga, al no poder inclinarse sus bases hacia arriba, opta por utilizar algún basamento o grada que complete la parte del decorado que sufre este inconveniente, por lo que consigue así complementar la falsa perspectiva. Cuando no es una parte sino toda la decoración la que requiere complementar a la perspectiva, entonces rehúye del basamento o grada y crea la pendiente o ligero plano inclinado del tablado como comenta en la escena trágica, al tiempo que precisa la característica de los basamentos: «...In questo caso farà da fare il detto basamento di basso relievo levato sopra il piano...».(48) 
Siguiendo a Vitruvio y de acuerdo con el criterio del teatro humanista, acerca de las categoríaś del mismo, señala los tres tipos fundamentales de decoración: la escena cómica caracterizada por calles, plaza pública, edificios, balcones, ventanas; la escena trágica, una construcción palaciega, con columnas, estatuas, frontispicios y con algunos objetos regios; la escena satírica, con árboles, hierbas con flores, buscando una similitud con la vitruviana pero rehuyendo el carácter licencioso con que en su momento se la dota, $y$, alcanzando, por tanto, un tono más pastoril sannazarino sin desconexión en su preferencia a Genga. ${ }^{(49)}$

Para la luminotecnia, Serlio busca la facultad óptica de las piedras preciosas: zafiro, esmeralda, rubí, topacio, etc. tratando de dar los colores propios de ellas, azul celeste, verde, rojo y amarillo, respectivamente; los cuales obtiene por procedimientos de mezclas como para el azul celeste, la de sal de amoniaco con agua, para el verde esta misma agua pero añadiéndole azafrán, para el rojo con vino tinto, para el amarillo con vino blanco, quienes tomarán distintas tonalidades según el tratamiento y la proporción de las mezclas.

Una vez estos líquidos son introducidos en recipientes de cristal, se colocan, detrás de los bastidores pintados, sobre una tabla y en la parte curva del recipiente de cristal, se instala otra tabla muy delgada agujereada, poniéndose detrás del recipiente de vidrio una lámpara lo que hace que se consiga una distribución de la luz por igual de estos colores transparentes. En el caso de que se quieran imitar los rayos de sol, como sucede en las «almendras» o «mandorlas», o que determinada zona del decorado requiera más luz, sobre el mismo sistema se aplica una antorcha situándose detrás de la misma un «bacín de barbero bien lucido y nuevo» ${ }^{(50)}$ cuya reflexión hará semejante esplendor.

Luz de escena propiamente dicha serían las que menciona al hablar de los tipos de escena: la gran cantidad de antorchas o candelas que se sitúan colgadas delante de la escena; a las que, a veces, en esa zona alta del frontis, sobre ellas, se dispone de un recipiente con agua y alcanfor que al arder, al mismo tiempo que da mayor intensidad de luz, despide buen olor.

Esta escena en relieve y de decorado, que alinea edificios en fila, por falsa perspectiva, disminuyendo su tamaño, a medida que se aleja del espectador, creando un efecto de profundidad hacia el que ya se había acercado Peruzzi al proyectar su puesta en escena de Bacchides(si) de Plauto, en Roma, en 1531, cumple una doble función, aunque el actor juegue delante del decorado y escasamente en la parte posterior de él, la de situar la acción y la de ocultar a los espectadores las entradas y salidas a escena de los «decitori».

Sobre este modelo de escena fija, escena «a la italiana» que codifica sistemáticamente en Serlio, el Vignola aporta la revitalización del periactoi-elemento del teatro clásico grecolatino del que también habla Vitruvio- sobre un escenario en relieve hasta las cajas del tercer término para que el actor tenga accesos desde el telón de fondo; por lo que el escenario angular se transforma en escenario giratorio, en cuanto a decorado, de cinco prismas equiláteros de base triangular a pentagonal, acordes con el número de cambios de escenas previstos que giraban sobre unos pivotes fijados en el suelo y accionados por cabestrantes o montacargas dispuestos bajo el tablado.

Estos eran una clase de armaduras altas colocados a lo largo de las diagona- 
les axiales de la escena que llevaban pintado o en relieve, sobre cada una de sus tres caras, una parte de la escena perspectiva, convergiendo en el fondo que estaba constituido por un prisma de base tres veces mayor que los otros.

B. Lanci también los utilizará, por el cambio rápido y simultáneo de escenas que permiten, en la representación de Los Fabis ${ }^{(52)}$ dada, en Florencia, en el Salón del Cinquecento, en 1567, al igual que los utilizaba Vasari. El ojo para Giorgio no era un elemento racional en la perspectiva ya que «...Ma non si debbe usare altra miglior misura che il giudicio dell'ochio; il quale, sebbene una cosa sarà benissimo misurata ed egli ne rimanga offeso, non resterà per questo di biasimarla) (53) sino un elemento asimilador de dilettantismo; actitud propia del manierismo florentino de este período en el que ya ha iniciado su abandono de búsqueda de lo intelectual. Su iconógrafo Borghini escribe al duque Cosme, para las fiestas de las bodas de Alfonso II con Bárbara de Austria, acerca de un "dettagliatto progetto dei fastosi apparati... $\rangle^{(54)}$ en el que priman los periactois, de los cuales da una detallada y gráfica explicación.

Instrumentos que continuará empleando el biógrafo de los artistas, Vasari, en la representación de la obra de G.B. Cini, La Vedova, ${ }^{(55)}$ en el Salón del Cinquecento, en 1596, para la que colaborará en los bocetos escenográficos B. Lanci. Obra con cambios rápidos en los tres primeros actos, provista de un decorado para cada acto, y después con escena fija figurada por una vista de Arcetri; las primeras escenas se desarrollan en un marco que figura la Plaza de la Señoría de Florencia ejecutada con perspectivas sobre estos prismas, en un intento de síntesis de las escenas trágica y cómica serlianas.

Los decorados se construyen para su implantación en perspectiva con uno o dos o tres puntos de fuga, como son las escenografias de B. Neroni, O. Scarabelli y otros escenotécnicos florentinos. Buontalenti continuará, como su antecesor y maestro, usando en sus trabajos estos instrumentos pero dándoles un nuevo diseño a base de formas cúbicas que se van superponiendo de mayor a menor; tal son los empleados en los «intermedios» y actos de la pieza, La Pellegrina, escenificada por él en el Teatro Médicis, en 1589, ${ }^{(56)}$ recitando el texto de G. Bargagli los miembros de la Academia de los Intronati de Siena, ${ }^{(57)}$ como parte de los festejos de las bodas de Fernando, gran duque de Toscana con Cristina de Lorena; comedia a la que acompañó, entre otros actos, una namaquía en el Palacio Pitti.

A principios del siglo XVII es nombrado escenotécnico del Teatro de los Médicis, Giulio Parigi, quien prepara la puesta en escena de la fábula en cinco actos de M. Buonarroti el Joven, El Juicio de París, en 1608, para solemnizar, junto con otras fiestas, como por ejemplo entre ellas, La Argonáutica de F. Cini que fue representada en el río Arno y para la que proyectaron las complicadas embarciones el propio Giulio, J. Ligosi y L. Cigoli, y ceremonias el matrimonio de Cosme, hijo de Fernando I, con María Magdalena de Austria; labor en la que sigue la línea de Buontalenti al realizar una escena fija del bosque, de implantación tradicional: sucesión de bastidores a lo largo de las perspectivas diagonales, única para los cinco actos de la comedia y seis diferentes para los respectivos «intermedios»; en los que figuran: $1 .^{\circ}$ ) El Palacio de la Fama, $2 .^{\circ}$ ) Astrea, $3 .^{\circ}$ ) Jardín de Calipso, $4 .^{\circ}$ ) Nave de Américo Vespucio, $5 .^{\circ}$ ) Vulcano, $6 .^{\circ}$ ) Templo de la Paz..$^{(58)}$

Las mutaciones, a fin de ocultar la perspectiva que permitía la mutación pa- 
ra la escena siguiente, se hacían por medio de diversos efectos, como en el caso del cambio del segundo intermedio, por medio de movimientos de nubes en $\mathrm{El} \mathrm{re-}$ torno de Astrea. Este tipo de efectos, en su diversa índole, son elementos tipológicos de la escenotecnia y escenografía italiana de estos años y están presentes tanto en el escenario como en los festivos carros triunfales, particularmente en éstos últimos en sus expresiones de «apariciones» y «glorias»; así como también los fuegos artificiales, en los que se distingue la inventiva de Buontalenti, apodado precisamente por esta actividad «el de la Girandole», renovador de una tradición que arrancaba desde el siglo XIV y se hacía especialmente espectacular en las fiestas de San Juan, la Asunción y onomásticas u otras festividades patricias.

A esta tipología de elementos aporta su novedad Alfonso Parigi el Joven quien propone, en una cuadratura arquitectócnica adornada con figuras emblemáticas, ya usual en los teatros italianos, próxima a los arcos del proscenio, una disposición escenográfica distribuida en un escenario con tres niveles en la última escena de su escenificación de Las Bodas de los Dioses,(59) espectáculo realizado en 1637, para las bodas del gran duque Fernando II con Victoria de la Rovere, en la cortile-patio del Palacio Pitti, al que proveía de una sucesión perspectiva de tres lugares distintos, la tierra, el infierno, el cielo, destinados a albergar tres coreografías simultáneas, ya que algunas figuras habían de aparecer en el cielo o tercer nivel.

Los referidos elementos tipológicos de la escenotecnia y escenografía italianas encuentran en Nicolo Sabbatini su tratadista. Sabbatini había trabajado en espectáculos realizados en Pesaro, en el Teatro del Sol, en 1637, en tipos de escena trágica y desértica con ruinas; en el tipo de la primera denotaba una influencia peruzzio-serliana y en el de la segunda, buontalentina, por lo que partiendo de estos artistas compendía toda la tipología hasta sus coetáneos, que aparece en 1638, en su obra Prattica de fabricar scene e machine ne teatri.

Habla de la perspectiva escénica; de las máquinas destinadas a crear efectos escénicos tales como nubes desdendentes, olas en movimiento; de los diversos medios para realizar cambios rápidos de escenas por medio de periactois de tres lados, que podía todavía hacerse más versátil poniendo vistas nuevas en los lados que ya habían sido vistos y que se retiraban de la escena; de telones pintados que podían pasar a través de los laterales; de cómo podían agruparse uno tras otro conjuntos de tres o cuatro bastidores laterales a lo largo de cada uno de los lados del escenario y cómo la parte posterior de cada grupo podía retroceder para cubrir el frente del segundo grupo trasero, cambiando de este modo la decoración; ${ }^{(60)}$ de la necesidad de transformar los dos primeros planos de edificios, pues quedaban fijos, cuando la escena siguiente era de bosque, a lo que señalaba: «...para remediar semejante inconveniente se podría construir al borde del escenario - se refiere al proscenio - un arco con columnas y estatuas, y componer en su interior el decorado...». ${ }^{(61)}$

Para dicho arco y otras formaciones de éstos sobre el foro plantea secciones curvas inclinadas de tela, en las que generalmente se pintan cielos, como novedad a las horizontales — piezas del mismo género, bambalinas, que completaban la decoración en su parte superior-que se colgaban del telar. Todo este dispositivo en conjunción con el arco del proscenio consigue el que «desaparecerán de la vis- 
ta los espacios interiores - se refiere a las cajas, entre bastidores, hombreras del escenario o entresijos del mismo, y principalmente a los precedentes, a los de primer término-, el escenario resultará muy bellamente adornado (...) en el interior de dicho arco se podrán poner un buen número de luces». ${ }^{(62)}$

\section{Maquinaria}

Brunelleschi alterna sus trabajos en el incipiente teatro cortesano con los de la Sacra Representación en el afán de recuperación que existía, y presentar innovados aspectos de la antigüedad medieval, como la de la fiesta de la Anunciación celebrada en Florencia, en la plaza o iglesia de San Felipe para la que inventó un mecanismo del Paraíso, en el que se veía en lo alto un cielo lleno de figuras vivas que se movían y desaparecían; máquina o «ingegni» ésta que goza de cierta familiaridad en el ambiente escénico de este primer período. También aparece en $\mathrm{Fe}$ rrara, sin embargo no como la inventada por el florentino, durante la escenificación de Amphitruo (Anfitrión) de Plauto, en 1487, que tuvo lugar en el patio del Palacio de la Casa d'Este, pretextada para aludir al futuro nacimiento de un Hércules en el linaje de esta familia, en la que ardió constantemente «un paraíso con estrellas y otras ruedas»; es decir, una iluminación tal vez a base de fuegos artificiales. ${ }^{(64)}$

En manos del de Vinci la Fiesta del Paraíso(65) que tendrá lugar en Milán, en 1490, bajo el mandato de Ludovico Sforza el Moro, en su corte, con motivo de homenajear a Isabel de Aragón en las bodas con un sobrino de éste, Giangaleazzo; el propio Ludovico proyectó la comedia y el poeta de la corte florentina B. Bellincioni se encargó de los versos. De Vinci(66) construyó un sistema planetario móvil, el Paraíso, en forma de medio huevo bordeado con los signos del Zodiaco con nichos para los planetas, en el que la montaña no se abre, con los siete cuerpos celestes que giraban en círculo por medio de grandes inventos, «ingegni», mecanismos, y, en el que los planetas estaban en la figura representados por hombres, quienes en su caminar sobre la escena significaban el giro de los planetas. El paraíso se movía por giros circulatorios, presentándose el hemiciclo de la esfera dividido por la mitad, rotando hacia adelante cada parte de las dos en que se dividía y al cerrarse quedaba transformado en un peñón recortado.

Leonardo, ${ }^{(67)}$ estando al servicio del rey de Francia, Francisco I, volvió a emplear su escenario giratorio en el Castillo de Lloux, en 1518, con motivo de la boda de una sobrina del monarca con el duque de Urbino, haciendo una escenificación del Paraíso semejante a la que realizara para los Sfroza.

Acerca de la puesta en escena de la obra de Angelo Poliziano, Orfeo, - tema de polémica sobre su estreno y su maquinaria, ${ }^{(68)}$ como una repetición de la Festa del Paradiso de Bellincioni, seguimos para lo primero a D'Amico y para lo segundo a Marinoni- ${ }^{(69)}$ prevista para Mantua, ${ }^{(70)}$ en 1480, pero que se dio en Ferrara en 1487, de Vinci había realizado los bocetos para la mantuana, en lo que se señalaba una montaña como elemento móvil ya que Orfeo desciende de la montaña, cantando con su lira, y se aproxima a la entrada de los infiernos; en el centro de la montaña aparece una puerta, la del Averno, donde Plutón está en una semiesfera como trono con algunos escalones. Al ser invocados los infiernos ante la puerta del Averno por Orfeo la montaña se abre y al momento se transforma para figurar dicho lugar satánico, quedando toda la escena ensombrecida repen- 
tinamente y con un solo punto de luz que se encuentra en la parte delantera de la caverna. El cambio de decorado está acompañado por los ruidos del Averno, ya que mientras la montaña se abre los diablos hacen resonar las «marmitas», especie de zambomba, que imitan ruidos y voces infernales, y la obra continúa sin interrupción; después cuando Orfeo vuelve a la tierra, la montaña se vuelve a cerrar y la pieza acaba con una bacanal.

El florentino, en el proyecto de este decorado que comprende una montaña donde se abre una gruta, elabora cada uno de los elementos de la escena: un sistema para levantar un poste o mástil, el andamiaje para el techo y el estrado, y el armazón de la montaña con el mecanismo de partes móviles representados en proyección horizontal. Leonardo propone, según Pedretti, ${ }^{(71)}$ dos secciones horizontales de la escena: la de arriba, lo alto, donde se encuentra la montaña y la de abajo que contiene el mecanismo, oculto, destinado a hacer que la montaña se abra; para unir las dos partes indica dos ejes verticales, de los que cada uno de ellos no parece haber sido hecho de una sola pieza que funcione de arriba a abajo, pero era necesario que el movimiento giratorio impreso a la parte inferior fuese transmitido de alguna forma a la parte superior. La solución más simple era la de hacer dos agujeros en el suelo: los dos ejes de una sola pieza habían podido ser insertados en los agujeros pero el techo de la sala habría impedido el que se levantaran a suficiente altura, por lo que debió de ser más práctico cortarlos en dos partes que se volverían a unir después, colocándose en la parte inferior de cada eje un brazo de hechura rígida en ángulo recto.

El mecanismo que diseña para la elevación de Plutón se basa en un sencillo sistema de contrapesas; los ejes pivotan en una u otra dirección, según que uno de los pesos esté más cerca a su destino o más pesado que otro. La rotación de los ejes hace que la montaña sobre la escena se abra o se cierre. ${ }^{(72)}$

Orfeo, en muy escasa medida, viene a ser una derivación del drama sacro que conjuga nuevos aspectos del teatro profano al valerse de los modos exteriores de la Sacra Representación: la anunciación no la hace un ángel sino Mercurio, cielo (monte) e infierno (bajos) son uno, etc.; con lo que Poliziano venía a fundir motivos del paganismo clásico con elementos técnicos del drama sacro, pero haciéndose muy notoria la presencia de los profanos.

Antecedentes de esta tendencia a la profanización de ciertos aspectos de la Sacra Representación y manipulación de textos ya se habían dado con anterioridad: la utilización de la Festa del Paradiso para que el Moro ganase el favor de Isabel de Aragón, al revestirse como Apolo, presentando a las Siete Virtudes, la saludaba como el «nuevo sol» del círculo de los planetas; la de Amphitruo en pro de la gloria para con los d'Este; et.

Leonardo tiene una concepción de la tierra como cuerpo humano, como máquina; son máquinas de la vida: «...la terra ha uno spirito di crescita è il suolo, le ossa sono le stratificazioni delle rocce che formano le montegne, il sangue l'acqua sorgiva...». ${ }^{(73)}$ Este modo de entender la cosmogonía lleva a interpretar que el instrumento que ilustra un principio de mecánica pueda ser concebido abstractamente, en neutralidad espacial; a este punto Leonardo parece aludir con rasgos espesos de fondo en sus diseños, así como sombras difuminadas para sugerir la atmósfera. 
Para la construcción de una carpa o toldo debajo de la cual se ha de colocar un decorado de bosque, proyecta un sistema en el que el poste o mástil se mantiene sujeto por un entramado de cuerdas, que camufladas por apliques de cartón piedra o materia semejante, de la que Jacobo de la Quercia había abierto el camino de su uso, ${ }^{(74)}$ figura que el tronco, base y fuste del mástil, representa a un árbol con ramas recortadas ellas reposan nidos y los objetos restantes de esta decoración aérea están suspendidos a las cuerdas atadas a los extremos de cada muñón de la rama. ${ }^{(75)}$

También construye autómatas, animales u objetos mecánicos, como el león, enviado a Francisco I de Francia, que al abrir el pecho muestra un ramo de flores de lis, y, la probable águila mecánica, a la que llama «l'ocel de la comedia», pájaro representado a lo largo de una cuerda o alambre, quien mueve sus alas por un sistema de ruedas y manivelas; así como del mismo modo un sistema de cuerdas para bajar el telón en la representación, proyectado en sus diseños de los años 1505-08. ${ }^{(76)}$ Esta compleja escenografia mecánica llena de efectos y de golpes de escena guarda una relación de precedente en la tradición brunelleschiana. Serlio nos habla de mecanismos cuyo efecto es muy del agrado del público y nos señala que se emplean en intermedios, «cuando la escena está desnuda de decidores», (77) o bien con la actuación de actores o con la representación de un «auto de figuritas", marionetas, guiñol; como pueda ser el vuelo de una golondrina, para el cual se fabricará de grueso cartón de colores y cortado en silueta que se colocará sobre una regla o listón de madera atravesado en cualquier arco, donde cogida al extremo de listón la cola de la golondrina, gracias al movimiento que dé al listón la persona metida en el arco, conseguirá este vuelo.

Igualmente el pase por el cielo de un planeta; para el que proyecta, sea pintado, realizado en cartón y cortado en silueta, colocándose en la parte posterior del último edificio de la escena, desde la que se tira atravesado un alambre que se conecta con una anilla sujeta por hilo negro, por razones de «invisibilidad», al cartón del planeta, el cual se irá desplazando al ritmo de la persona que estando al otro extremo maneje este hilo negro. Tanto para el movimiento de la golondrina como para el del planeta, aconseja el que estos «vuelos» vayan acompañados de sonidos y voces que les sean propios: a la primera, suaves y al segundo, truenos, relámpagos, fulgores. ${ }^{(78)}$

La escena que figura Pisa y el «ingenio» del «sol» que pasa, reclamando a la unidad de tiempo, realizado por Bastiano de Sangallo para la representación de El Comodo en 1539, es un mecanismo que trabaja en un intermedio formando parte de dicha escenificación en la que el cielo se abre, sobre la perspectiva de la ciudad de la torre inclinada, descubriéndose a la Aurora, vestida de una ropa de gasa ligera y resplandeciente de plata y oro. Semejante máquina pero más amplia y fastuosa trabaja en La Cofanaria, en un intermedio, donde la bóveda del cielo se abría y un nuevo cielo, todavía más brillante, se mostraba a los espectadores; en los rayos luminosos de este firmamento, Paraíso, estaba Venus desnuda, o con traje que daba ilusión de desnudez, y adornada de guirnaldas de rosas y mirtos en un carro dorado conducido por dos cisnes, a la que acompañaban las Gracias, desnudas también, y las Cuatro Estaciones. Todas reunidas en la misma nube, que lentamente descendía, cantando sobre la tierra donde se encontraban al 
dios alado del amor, igualmente desnudo, seguido por la Esperanza, la Caridad, la Alegría y la Tristeza, al compás de una suave música y con perfumes que se expandian por la sala; la Diosa del Amor, tras entonar un canto en el que transmitía su mensaje, en el mismo carro sobre nubes volvía al Olimpo, mientras las Gracias repartían flores y el Amor, cantando, iba en busca de Psique al tiempo que el cielo se volvía a cerrar sobre Venus. ${ }^{(79)}$

Esta pieza y otrás representaciones y festejos integraban la serie de actos para las bodas de Juana de Austria con Francisco de Médicis, en 1565, siendo el último, del que ya hemos hecho referencia, una representación en la iglesia del Santo Espíritu de La Anunciación, en la que Vasari vuelve a empear la misma máquina que suponía un nuevo avance en los útiles mecánicos: «...fu invence di carattere sacro (...) era una novità rispetto a precedenti festeggiamenti nuziali (...) poich'veniva a riessumare, con mezzi nuovi e tecnicamente più scaltriti, la vecchia e gloriosa pratica degli ingegni brunelleschiani applicati alle sacre rapresentazioni...». ${ }^{(80)}$

Los intermedios de La Pellegrina, gracias a Buontalenti, vienen a reunir y sintetizar la serie de máquinas en boga del momento. En el primero, La Armonía de las Esferas, según la conocida teoría de Platón revitalizada de nuevo por los humanistas de Renacimiento, se iniciaba con Harmonía Doria que abría la representación bajando, desde un cielo en el que había tres grupos de deidades, en una nube a la cual servía de decorado de fondo una perspectiva de Roma; deidades celestes entonaban un cántico y una vez acabado éste, en la parte alta de la escena, aparecían los Siete Planetas, Astrea, las Parcas y la Necesidad.

En el segundo, Debate de las Musas y las Piérides, por quienes mejor cantaban, ante el desafio de las nueve doncellas que quisieron rivalizar con las Musas; aparecen en escena, en número de doce, sobre la pendiente de un monte, el Helicón, acompañadas de la ninfa Hamadríade, quedan convertidas, las hijas de Píero, en garzas, trocándose a vista sus vestidos nínfeos por los de esta ave.

En el tercero, La lucha entre Apolo y Pitón, aparece un bailarín con máscara que representa a Apolo, tras su danza es sustituido por una figura del mismo dios amoroso, autómata de cartón, que volando desde el cielo asaetea a la serpiente Pitón.

En el cuarto, El Infierno, lo constituye un paisaje de rocas de cuyos laterales superiores surgen llamas, irguiéndose a medio cuerpo desde el foso la figura de Satán; el firmamento está orlado de divinidades y en un carro sobre una nube, más bajo que las deidades, aparece una figura celestial.

En el quinto, Anfítrite y la nave de Arión, se abre la escena con Anfitrite, nereida, reina del mar, acompañada de nereidas o ninfas marinas y tritones o delfines, adonde arriva Arión a bordo de una galera cantando al son de un arpa.

El sexto, con el que se cierra la representación, Los Dioses envían a los mortales la Armonía y el Ritmo, viene a ser una especie de repetición del primero al que se suman Apolo con su lira y la diosa de la Fortuna. ${ }^{(81)}$

Por estas mismas fechas y fiestas de las bodas de Fernando, gran duque de Toscana con Cristina de Lorena, también se organiza un espectáculo donde las escenas de metamórfosis fueron utilizadas por primera vez en una Representación Sacra: La Exaltación de la Cruz de G. Cecchi, producida por una orden reli- 
giosa y puesta en escena, con aparato emulador a los buontalentianos, por L. Landini.

Todo ello viene a suponer en un momento determinado de la evolución de los géneros, 1589, con la incorporación de la escenotecnia más avenzada, tanto por la Sacra Representación como por la comedia profana, de una clara identificación de los mismos. ${ }^{(82)}$

Acerca de algunos efectos: trueno, relámpago, rayo, vuelve a ser Serlio quien nos explica el modo de obtenerlos, aunque Buontalenti, como maestro especializado en ellos, los ejecute innovados; el trueno tiene lugar en el suelo de la parte alta de la sala, sobre el que se hace correr una gruesa bola de piedra; el relámpago se hará en la parte alta de detrás del decorado de fondo, donde habrá una persona que dispondrá de una cajita llena de polvo de barniz que arrojará hacia lo alto ante la faz de una candela encendida; el rayo se fabrica tirando un alambre dorado desde un punto lejano que atraviese la escena de lo alto hasta un punto bajo, donde irá cogido a un carrete y al soltarse el extremo del punto lejano dará este efecto ${ }^{(83)}$

Las máquinas que permiten los vuelos y sus distintos tipos según la clase del mismo: oblicuo, vertical, etc., también llamadas "glorias», son mecanismos con varios juegos de poleas y fuertes andamios que sostenían la tramoya y los actores; estos juegos de poleas estaban instalados en la parrilla o peine y accionados los sistemas de cuerda del telar permitían el efecto de los «ingegni», como en el Aristóteles, la aparición y vuelo de la Aurora; en Vasari, la de Venus con las Gracias y las Estaciones; en Buontalenti, la de Harmonía Doria, la de Apolo autómata; en Landini, la de Dios Padre, etc.

Para la aparición o desaparición de un personaje u objeto del escenario se hacía a través de una trampa o escotillón en el foso que mediante una plataforma, máquina de tradición vinciniana, lo conseguía; como en la ladera del monte Helicón del segundo intermedio de La Pellegrina, en el que el ascenso de la máquina llegaba a alcanzar hasta siete metros de altura «y no poca maravilla producía en el público el hecho de que el espacio que la ocultaba delante no alcanzaban los tres metros $)^{(84)}$.

Los efectos laterales del escenario se hacen mediante "carras» que son máquinas que aparecen en escena desde las cajas o entre bastidores; para esto el «ingegni» o máquina se coloca sobre una plataforma que se introduce en escena mediante el empuje de personas que están ocultas en las hombreras o un sistema de tracción desde el foso; el de la Girandole hace uso de la carra en el quinto intermedio de la obra de Bargagli al hacer asomar la proa de la galera de Arión en el tercer término del lateral derecho.

Buontalenti no sólo creaba efectos con «ingegni», con máquinas, en la escena sino que dominaba una serie de efectos «mágicos» o trucos que empleaba en la misma, como la transformación de las Piérides en garzas, o en otros actos cortesanos: el año 1600 en el banquete de bodas de María de Médicis con Enrique IV de Francia, en el Salón del Cinquecento, inventó una serie de trucos para maravillar a los invitados; uno de ellos consistía en cubrir las mesas con espejos que en un momento determinado giraban y reflejaban las imágenes de las damas senta- 
das a la mesa, lo que invitaba a la coquetería femenina de admirarse y retocarse el peinado. ${ }^{(85)}$

Unida a la tipología de la escenotecnia y la escenografía, la de la máquina consagrada por Bernardo, tendría continuidad en sus discípulos, especialmente con A. Parigi en sus prácticas escénicas, con simplificación y perfeccionamiento, y en la sistematización teórico-práctica de Sabbatini.

El presente trabajo es un aspecto sintetizado sobre la génesis y desarrollo del panorama escenotécnico italiano del Renacimiento y primer Barroco que, como legado, los artistas Fontana, Lotti y Del Bianco traerán a España, donde ejercerán influencia notoria en los dramaturgos de nuestro siglo aúreo.

\section{NOTAS}

(1) J. Jacquot: «Sénèque, la Renaissance et nous» en Les tragédies de Sénèque et le théatre, $\mathrm{Pa}$ rís, 1973; pág. 281.

(2) Ver Vitruvio: Arquitectura, Barcelona, 1970; págs. 121-24.

(3) A. Chastel: «Cortile et théatre» en Le lieu theatral a la Renaissance, París, 1968; pág. 42.

(4) Ver Vitruvio: Arquitectura, op. cit.; pág. 124.

(5) K. Macgowan y W. Melnitz: Las edades de oro del teatro, ( ${ }^{\mathrm{a}}$ ed.), México, 1964; pág. 58.

(6) Ver A. Chastel: «Cortile...» en Le lieu..., op. cit.; págs. 41-42.

(7) K. Macgowan y W. Melnitz: La edades..., op. cit.; pág. 58.

(8) M. Berthold: Historia social del teatro, vol. 2, Madrid, 1974; pág. 10, lo da equivocado ya que nombra esta obra como perteneciente a Terencio..

(9) Ibídem. pág. 10. 476.

(10) J. Jacquot: «Les types de lieu théâtral et leurs transformations» en Le lieu..., op. cit.; pág.

(11) M. Berthold: Historia social..., op. cit.; pág. 18; la sitúa en el Castillo de Sant Angelo. Aquí preferimos seguir a D'Amico que sostiene, fue en el Vaticano; S. D'Amico: Historia del teatro dramático, vol. II, México, 1961; pág. 22.

(12) M. Berthold: Historia social..., op. cit.; pág. 19.

(13) S. D'Amico: Historia del teatro..., op. cit.; pág. 22.

(14) A. Pinelli y O. Rossi: Genga architetto, Roma, 1971; pág. 107.

(15) F. Cruciani: Teatro nel Rinascimento. Roma 1450-1550, Roma, 1983; pág. 447.

(16) Ibídem.

(17) M. Berthold: Historia social..., op. cit.; pág. 27.

(18) A. Chastel: «Cortile...» en Le lieu..., op. cit.; pág. 43.

(19) Ibidem.; pág. 46. 
(20) J. S. Ackerman: Palladio, Madrid, 1981; pág. 43.

(21) F. Irace: «Presentazione» en S. Serlio: I sette libri dell'Architettura, Venezia, 1584, (ed. fac.), vol. I. A. Forni Editore, 1978; pág. 27.

(22) G. Marzari: La Historia de Vicenza, Venise, 1591; pág. 117. Lo toma L. Schrade: La representation d'Edipo Tirano au Teatro Olímpico (Vicence 1585), París, 1960; pág. 45.

(23) J. S. Ackerman lo atribuye a una mala interpretación del texto vitruviano; en Palladio, op. cit.; pág. 45.

(24) L. Schrade: La representation..., op. cit.; pág. 45.

(25) F. Petrarca: Triunfos, (ed. lilingüe), Madrid, 1983; págs. 39-45.

(26) K. Macgowan y W. Melnitz: Las edades..., op. cit.; pág. 63.

(27) Ver A. Della Valle: Palladio: La sua eredita'nel mondo, Venecia, 1980; pág. 258.

(28) L. Zorzi: Il teatro e la città, Torino, 1977; pág. 94.

(29) Ibídem.; págs. 197-98.

(30) E. Garbero: «Il salone dei Cinquecento in Palazzo Vecchio» en Firenze e la Toscana dei Medici nell'Europe del Cinquecento. Il potere e lo spazio. La scena del principe. Consiglio d'Europa. Sedicesima Esposizion Europea di Arte, Scienzes e Cultura, Firenze, 1980; pág. 325.

(31) A. M. Petrioli: Carri trionfali e costumi per la genealogía degli dei (1565), Firenze, 1966; pág. 8.

(32) L. Zorzi: «Il teatro mediceo degli Uffizi e il teatrino detto della Dogana» en Firenze e la..., op. cit,; pág. 355.

(33) Ver Vasario: Vida de artistas, vol. II, Barcelona, 1957; pág. 287.

(34) Vasario: Vidas..., op. cit.; pág. 288.

(35) G. C. Argan: Brunelleschi, Madrid, 1981; pág. 132.

(36) K. Macgowan y W. Melnitz: La edades..., op. cit.; pág. 58.

36.

(37) K. T. Steinitz: «Le dessin de Léonard de Vinci pour La Danae» en Le lieu..., op. cit.; pág.

(38) E. Garbero: «Il salone...» en Firenze e la..., op. cit.; pág. 325.

(39) S. Serlio: I sette..., op. cit.; pág. 18.

(40) Ver Vasario: Vidas..., op. cit.; págs. 77 y 78.

(41) Alberti está en semejante parecer cuando habla de la función del pintor. Ver A. Blunt: $L a$ teoría de las artes en Italia, Madrid, 1979; pág. 25.

(42) Ver L. da Vinci: Tratado de Pintura, Madrid, 1982; pág. 116.

(43) S. Serlio: I. sette..., op. cit.; pág. 19.

(44) L. da Vinci: Tratado..., op. cit.; pág. 97.

(45) S. Serlio: I sette..., op. cit.; pág. 19.

(46) Ibídem.; pág. 49.

(47) Ibídem.; pág. 50.

(48) Ibídem.

(49) Ver S. Serlio: I sette..., op. cit.; págs. 51 y 52. Lo retoma de un Anónimo italiano de 1578; se trata del aparato escénico que G. Genga realizó probablemente en Pesaro, en 1525. También lo reproduce, A. F. Ivaldi: Le nozze Pio-Farnese e gli apparati teatrali di Sassuolo del 1587, Génova, 1974; pág. 29.

(50) S. Serlio: I sette..., op. cit.; pág. 52.

(51) F. Cruciani: Teatro nel Rinascimento..., op. cit.; págs. 512-13.

(52) L. Zorzi: Il treatro e..., op. cit.; 103-05.

(53) G. Vasari: Le opere di Giorgio Vasari, (ed. de G. Milanesi), vol. I, Firenze, 1878-82; pág. 151. Lo cita G. C. Bauer: «From architecture to scenography: the full-scale model in the baroque tradition» en La scenografía barocca, a cura di A. Schnapper, Bologna, 1982; pág. 147. También lo recoge A. Blunt: La teoría de las..., op. cit.; pág. 105, citándolo como G. Vasari: Vidas, IV. Síntomas a este fenómeno, aunque mínimamente, se anuncian en L. B. Alberto: Los diez libros de Architectura, 
(ed. fac., Madrid, Alonso Gómez, 1582), Valencia, 1977; pág. 281.

(54) L. Zorzi: «La scena 'all'italiana' (Sangallo, Vasari, Buontalenti)» en Firenze e la..., op. cit.; pág. 339.

(55) Ibídem. Sobre el comportamiento de la escana a la italiana en España versa mi comunicación: «La gran maquinaria en comedias mitológicas de Calderón de la Barca» en Actas de VIIJornadas de Estudio de Almagro (en prensa).

(56) L. Zorzi: «La scena 'all...» en Firenze e la ..., op. cit.; pág. 340.

(57) Se había invitado a A. Piccolomini para la realización del texto pero él declinó la oferta, que aceptó Bargagli, como apunta N. Borsellino: Rozzi e Intronati, $\left(2^{\mathrm{a}} \mathrm{ed}.\right)$, Roma, 1976; págs. $110-$ 11.

(58) F. Berti: «I bozzeti per i costumi» en Firenze e la..., op. cit.; pág. 368.

(59) E. Garbero: «Filtri dal Buontalenti e dal Parigi» en Firenze e..., op. cit.; pág. 382.

(60) N. Sabbatini: Pratique pour fabriquer scenes et machines de theatre, (ed. fac. sobre la italiana de Rávena de 1638), Neuchatel, MCMXLII; lib. II, caps. XXVIII y XXXVIII.

(61) Ibídem.; pág. 22.

(62) Ibídem.

(63) Ver Vasario: Vidas..., op. cit.; págs. 103, 104, 105.

(64) J. Burckhardt: La cultura del Renacimiento en Italia, Barcelona, 1971; pág. 236.

(65) Alcanza una nueva visión, como apunta L. Zorzi: Il teatro..., op. cit.; págs. 75 y 76.

(66) Aunque no compartimos el aspecto del movimiento de los actores, por su interés técnico, hemos sintetizado el criterio de M. Berthold: Historia social..., op. cit.; págs. 34-35.

(67) C. Pedretti: «Dessins d'une scène, exécutès par Leonard de Vinci» en La lieu..., op. cit.; pág. 27.

(68) Especialmente en ésta, entre C. Pedretti: «Dessins...» en Le lieu..., op. cit.; págs. 31-34 y K. T. Steinitz: «Le dessin de Leonard...» en Le lieu..., op. cit.; págs. 39-40.

(69) A. Marinoni: Il Regno e il Sito di Venere, Firenze, 1957. Lo sigue C. Pedretti: «Dessins...» en Le lieu..., op. cit.; págs. 28 y 31.

(70) S. D’Amico: Historia del teatro..., op. cit.; pág. 8.

(71) C. Pedretti: «Dessins...» en Le lieu..., op. cit.; pág. 27.

(72) Ibidem.; pág. 28.

(73) A. Vezzosi: «Ingranaggi di Cosmogonía» en M. Cianchi: Le machine di Leonardo, Firenze, 1980; pág. 8.

(74) Ver Vasario: VIdas..., op. cit.; pág. 17.

(75) C. Pedretti: «Dessins...» en Le lieu..., op. cit.; pág. 29.

(76) Ibídem,; pág. 27.

(77) S. Serlio: I sette..., op. cit.; pág. 51.

(78) Ibídem.; pág. 52.

(79) A. Beijer: «Visions célestes et infernales dans le théatre du Moyen-Age et de la Renaissance» en Les Fêtes de la Renaissance, vol. I, París, 1973; págs, 406, 407.

(80) A. M. Petrioli: Carri trionfali..., op. cit.; pág. 9.

(81) L. Zorzi: «Il teatro mediceo...» en Firenze e la..., op. cit.; págs. 358 y 360 . Para una tentativa de tratamiento de escena palaciega en el corral, mi comunicación: "Significados visuales en "El burlador de Sevilla y convidado de piedra" de Tirso de Molina» en Actas de las VIII Jornadas de Estudios de Almagro (en prensa).

(82) A. Beijer: "Visions...» en Les Fêtes..., op. cit.; pág. 409.

(83) S. Serlio: I. sette..., op. cit.; pág. 52.

(84) L. Zorzi: «Il teatro mediceo...» en Firenze e..., op. cit.; pág. 358.

(85) P. Marchi: «Il banchetto di corte» en Firenze e..., op. cit .; pág. 330. Sobre el efecto de los espejos, mi artículo: «El espejo cóncavo en Calderón y Valle-Inclán» en Crítica Hispánica, Eası Tennessee State University, U.S.A. (en prensa). 